\title{
The Exploration of Characteristic Urbanization Way to North Area of Jiangsu
}

\author{
Yi Xi \\ Business School, University of Shanghai for Science and Technology \\ 516 Jun Gong Road, Shanghai 200093, China \\ E-mail:cyflxy5956@126.com \\ Dianqing Song \\ Business School, University of Shanghai for Science and Technology \\ 516 Jun Gong Road, Shanghai 200093, China \\ E-mail: songdianqing17@163.com
}

Received: February 21, 2011 Accepted: March 10, 2011 doi:10.5539/ibr.v4n3p156

\begin{abstract}
The urbanization is a process which urban social and urban civilization forming gradually. On the way of urbanization, we develop the economy first and improve the quality of people's life later. Although it help to avoid the "over-urbanization" phenomenon which usually appeared in developed countries, but it also led to the economy imbalance of our country. Due to there are some differences in each natural endowments so the three region of Jiangsu province have different feature in the road of urbanization. This article compares the urbanization development status and characteristics of the northern, middle and southern region of Jiangsu, review the experience of southern district then try to provide some measures to narrow the gap among them.
\end{abstract}

Keywords: Urbanization, Jiangsu, Small towns, Available measures

\section{Basic theoretical definition}

\subsection{Urbanization}

Urbanization process initially originated in Britain industrial revolution, as the birthplace of urbanization, developed countries like America and European acted as a benchmarking role in this tendency, so the level of their urbanization is quite high. The rate of European is $51.2 \%$ and 63.9 for America in 1950. With the time being, it is $76.8 \%$ and $80.2 \%$ respectively in 2003, and soaring into $79 \%$ and $87 \%$ in the end of 2007 .

Due to China suffered from the common oppression of feudalism and imperialist, economic development is slow. But under the guidance of reform and opening up policy our advantage backwardness is obvious. Professor Gu Chaolin has put forward the definition of urbanization which full of Chinese characteristic: The urbanization is refers to the increase in the number of towns and the expansion of cities' scale which all leading people gathered to the town in certain period. It is also a process that makes material and spiritual civilization of city to be spread around, derive the new spatial form and geographical view in the evolution of regional industrial structure.

\subsection{Rate of urbanization}

The rate of urbanization is an important standard which can measure the development level of regional economic. It is also the digital performance of urbanization. In this article, we use the proportion which urban shared in the total population as the comprehensive index of the rate of urbanization. We can learn the economic development of an area or a country in a period intuitionistly through this index.

\section{The simply introduction of Jiangsu}

\subsection{Location}

"Su" is referred to Jiangsu province, it is located in the eastern coastal center of mainland which between $116^{\circ} 18^{\prime}-121^{\circ} 57^{\prime}$ of east longitude and $30^{\circ} 45^{\prime}-35^{\circ} 20^{\prime}$ of north latitude. It is near to yellow sea in the east direction, adjacent to Anhui province in the west, border to Shandong province in the north side and close to Zhejiang and Shanghai province. Jiangsu province is located in the beautiful and fertile Yangtze River triangle states which have vast plains including the yangtze-huaihe plain, Jiangsu HuangHuai plain and the eastern coastal plain, so it has excellent natural conditions, economic foundation is better. 


\subsection{Area}

The whole area of Jiangsu province is about 10.26 square kilometers which account for $1.1 \%$ of all nations. Among this, the area of plain is about 7.06 square kilometers, while for water is 1.73 million square kilometers. The length of coastline is 954 kilometers, the area of arable land is 472 million hectares.

\subsection{Major cities and the three regions}

There are 13 cities in Jiangsu province including Nanjing which is the capital of Jiangsu, others are Suzhou, Wuxi, Changzhou, Zhenjiang, Yangzhou, Nantong, Taizhou, Xuzhou, Lianyungang, Huaian and Suqian, Yancheng. According to the relative location of changjiang river, these cities can be divided into three regions, Sunan region including the former five cities, the middle three cities is belong to Suzhong region, and the last five cities is in Subei region.

\section{The simply developing introduction of each region}

Jiangsu is a big economic province. In the process of urbanization, many economic indicators are listed in the front row of whole nation, however the internal economic development of Jiangsu is uneven. Regional developmental difference is bigger, especially in the three region mentioned above.

\subsection{GDP and $A G D P$}

Table 1 is the comparison of GDP and AGDP in three regions over the past five years, we can clearly see that although the regional land area and population of Subei accounted for $52 \%$ and $44.5 \%$ respectively of the entire province, also it has abundant resources and the geographical location is quite important, but economic development level is very low. Measured of the per capita GDP, Sunan is four time of Subei region.

\subsection{The urbanization rate of each region}

According to data in table 2 we can make out the figure 1. From the developing trend of the past decade, the urbanization rate of each region of Jiangsu shows a remarkable ascendant trend, this indicates that economic development and urbanization are all accelerating. But use it to compare with the average province urbanization rate, we can know that Sunan province is always in the upper of line while Suzhong and Subei region is always in the below area of line. In addition, the gap between Subei and average is the biggest. So it reflects that the urbanization rate of Jiangsu is still uneven, we should create good conditions, foster those areas which have natural endowments to speed up economic development.

\section{To speed up the economic development rate of Subei province}

\subsection{The experience of Sunan Mode}

\subsubsection{Use geographical advantages, accept the radiation of Shanghai}

Due to there are shanghai-Nanjing railway, shanghai-Nanjing expressway and provincial highway connections between Shanghai and Sunan region, so transportation is very convenient. Since July of 2010, after the opening of inter-city railway, sunan region is directly entering into the one hour economic circle of Shanghai, so the radiation effect become more remarkable. Kunshan as the closest town with Shanghai, its momentum of development is quite rapidly, it already in the list of top 100 cities of nation.

\subsubsection{Building good soft and hard investment environment under the leadship of government}

The level of investment environment has a directly impact on the effective of investment promotion. Good environment construction not only to improve the city's infrastructure, but also need more government concern on soft environment construction, tax revenue, the administrative examination, approval, system innovation and so on. Government should be trying their best to provide the needed of investor in policy and other respects.

4.1.3 Multiple investments, cluster development in order to promote the industrial upgrading innovation

Based on the solid industrial foundation and economic strength to promote industry transformation, then in order to promote innovation from industrial structure upgrade, technical improvement and so on. Through introduced the hi-quality foreign money, guiding foreign investment industries to achieve market change technology, with labor changing technology, accelerate the industrial structure and the pace of technological updates. In the meantime, we should be focus on building the a good innovative environment, cultivating the creative talents, encouraging innovational enterprise, creating innovative regions, thus finally realize industry transformation and upgrading which character multiple push, endogenous primarily, sustainability.

\subsubsection{Through gathering and space reconstruction, realize the health urbanization of city}

Government should be guide the population gathering into the heart of city, release the development potential 
agglomeration of services industry then promote the industry development. Standing on this, what should government do is that to create a definite area center, improve the service function and reconstruct the reasonable space.

\subsection{How to develop the Subei region well}

\subsubsection{Formulate the character measures according to the regional condition}

Central city act double function of concentration and radiation in the regional development. If Subei region want to catch up and realize the great-leap-forward development, the government must be put heavy attention in cultivating a strong central city, creating the new economic growth spot and improving its economic function also its employment capacity in order to strengthen the ability of absorbing rural surplus labor. So the government should be use SWOT to analysis the actually condition then formulate the measures based on this.

\subsubsection{Xuzhou}

Xuzhou is the largest city of Subei region, also is the most important subway junction in Jiangsu province and the whole nation. It owns their local legislative power approved by the State. So I think we should make heavy concern in this city, effort to cultivate it to become the new economic growth pole of Subei region. By strengthening the urban traffic, financing market and currency construction, expanding its city scale, then further enhance the function of Xuzhou's role as the important traffic hub, also Eurasian continental bridge east-central city and business. Due to Xuzhou is rich of coal, so it is the important power base of East area. It also has lots of coal, well salt, iron, titanium, marble, and limestone which quality is very good. So the government should be make good use of these mineral resources, introduce advanced technology and experience actively, develop recycling economy, eliminate the development mode of treatment after pollution, insist to develop sustainability.

\subsubsection{Lianyun gang}

Lianyungang is the biggest seaport of Jiangsu province, the most economic and convenient ports of middle and west area, also is the east bridgehead of the new Eurasia bridge. It is determined by the state as one of the first batch of the 14 coastal opening cities since 1984. From the geographical conditions, Lianyungang is similar with Shanghai and Nantong but the economic development level is different strikingly.

I think the development of Lianyungang should position from below three aspects: 1.Take good use of its advantage of seaport, make more concern in developing its function of international container intermodal transition port between European and Asia, also service to its economic hinterland in the container transportation. 2. Together with yanwei port, Hantou port which belong to Hanzhou bay coast then build a China's future large harbor group so that they can use the seaside unique topography to develop wind energy, tidal energy and so on in order to provide the green energy for large-scale sea-front industrial. 3. Dig the tourism resources of Lianyun gang, form one-stop services consist of a series of tourism scenic like huaguo mountain, harbor beach, moya carved stone and seafood supplemented service then develop the city's third industry.

\subsubsection{Yancheng}

Yancheng coastal waters is the only inland waters without red tides, binhai port is one of the best depth conditions in Jiangsu coastal, now the capacity of Sheyang port can reach 530 million tons per year. Based on above advantages, I think if make these port cooperate with Lianyun gang, function as its satellite port, so they can develop the shipping, warehousing and other manufacture industry then form a coastal economic zone.

Yacheng is rich of oil and gas resources. There are about 10 million square kilometers of the yellow sea oil storage sedimentary basin in its coastal and offshore area, occupies No.2 of the national Marine oil-gas sedimentary basin. Therefore we should focus on developing the sea resources of yancheng, form the industrial cluster development consist of its salt industry, Marine fishing, aquaculture, oil and gas resources development and marine dynamic development.

With the development of economy, people's demand of life quality and health is higher and higher. Yancheng as the largest agricultural and sideline production base of Jiangsu should seize this opportunity focus on developing the non-public hazard green organic food, and make deeply process to these primary agricultural products, extend the industry chain, realize increasing economic value together with promoting employment rate.

\subsubsection{Huaian}

Judging from the geographical position, see from lateral level, huaian is an important node bond of Xuzhou, Suqian and Yancheng, while see from longitudinal, it is also the necessary lead from Lianyungang to Nanjing. Huaian's domestic highway, railway, waterway extends in all directions, there are five highway like Beijing-shanghai, NingSuXu, huai salt, SuHuai and NingHuaiw will through its area. So I think that huaian should be developed as the 
sub-junction of Subei area's internal transport. Through transform its soft and hard environment, introduce foreign investment actively and establish industrial park vigorously, benefit surrounding area. Due to huaian is full of historical culture, also have numerous celebrities, so the ecological culture and travel should be good development localization.

\subsubsection{Suqian}

Suqian is the hometown of the famous aquatic product, wine and silkworm cocoon, it is also the center of biological evolution, a center of human origin, so it is well known as the earth's" life sanctuary." Due to the Hongze lake streams across this city, so this city also famous of its crabs, whitebait and rich cultural and natural tourism resources. Considering these advantages, I believe that this city should be defined as a tourist city, relying on aquatic and liquor, improve the tourism industry, at the same time, make deeply processing on silkworm products then meet the demand of people in natural product.

\subsubsection{Play the leading role from top to down then realize the coordinated development}

The defects of economic person doomed that they cannot exert governmental functions as public managers. But because the development level of Jiangsu internal area have quite big differences, so whether from urban modernization or towns urbanization, its coordinated development need government function as a leading role to promote from top to down. Only via this unified planning, encourage reasonable and orderly flow of funds and population, then optimizing the spatial relationship and industrial contact between towns, thus promotes the coordinated development of each city in Jiangsu.

\subsubsection{Improve the urban land use system, alleviate the land contradiction}

Based on stabilize and improve the land contract relations, according to the principle of voluntary with reasonable paid, make the reasonable transfer of the right to use the land. Guide and encourage the farmers which left their hometown transfer their right to use land with reasonable compensation then realize the optimize of resources. Meanwhile government should try to use the format of differential rent, exchange the land which farmers owned in hometown into the land which belongs to town in certain proportion then service for these farmers who came into city for job. Via this exchange, the farmers who worked in cities can have their own live and business land in town, so it can solve the contradiction of land fundamentally, and reducing land desolate also the irrational use.

\subsubsection{Eliminate the dual structures, reforming the household registration system}

Make the small towns below county as pilot, free the account limited to get experience. Then extended to large and medium-sized cities when all conditions matured gradually, execute the policy of birthplace fixed, residence registration according to regulations. Use the ID system instead of the household registration system gradually, promote the new residence enjoy equal treatment in employment, doctor, children education with the original urban residents then in order to eliminate the artificial barriers of talent flow, realize the reasonable flow of talent and capital.

\subsubsection{Agglomeration development and retain talents}

Agglomeration development has the scale effect, it can formed benign competition relationship between each economic subject. Enterprise in order to keep or gain more competitive advantages, invest numerous capital to promote the technology innovation. This investment enhanced his ability to innovate virtually. Subei region of Jiangsu province should carry on the agglomeration development, make good use of its low cost advantage, then realize continues innovation in the process of competition so that to keep the core competitiveness of the enterprise.Each city must provide vast development platform and good living environment for talent in order to retain them, realize the talent's role in competition.

\section{Conclusion}

The 17th session of the fifth session proposed the twelfth five year plan, there is appeared a new concept "inclusive growth" in it. This suggests that in the next five years, state will pay more attention to narrow regional gap and realize the regional coordinated development while raising the level of urbanization. Jiangsu as the guide of urbanization, the rapid development of Subei region has important significance for rural modernization and urbanization process. This article put forward the characteristics of urbanization path according to the advantage of each Subei city. This can be as a reference in the urbanization exploration of other underdeveloped areas.

\section{References}

Duan, Ruijun. (2008). Euramerican developed country urbanization experiences and their inspiration to China. City. 10:54-57. 
Gu, Chaolin, Yu,Taofang \& Li,Wangming. (2008). China's urbanization: pattern, process, mechanism.Beijing. Science- Publishing.

Zhang, Weidong \& Fan, Yanchao. (2008). Jiangsu statistics yearbook. China statistical publishing.

Hong, Yingxing \& Chen, Wen (2000). The new development of urbanization model - take Jiangsu for example. Economic research. 12:66-71.

Shan, Daming, Sunan \& Subei. (2004). The economic development comparative analysis. Economic BBS. 6:37-39

Tabel 1. GDP and AGDP of three Jiangsu regions from 2004 to 2008

\begin{tabular}{|c|c|c|c|c|}
\hline year & indication & Sunan region & Middle region & Subei region \\
\hline \multirow{2}{*}{2004} & The GDP share of total province (\%) & 61.8 & 17.5 & 20.7 \\
\cline { 2 - 5 } & Average person GDP(RMB) & 42965 & 15687 & 10004 \\
\hline \multirow{2}{*}{2005} & The GDP share of total province (\%) & 62.6 & 17.6 & 19.8 \\
\cline { 2 - 5 } & Average person GDP(RMB) & 50508 & 18591 & 11148 \\
\hline \multirow{2}{*}{2006} & The GDP share of total province (\%) & 62.5 & 17.9 & 19.6 \\
\cline { 2 - 5 } & Average person GDP(RMB) & 48559 & 23501 & 13699 \\
\hline \multirow{2}{*}{2007} & The GDP share of total province (\%) & 62.4 & 18.1 & 19.5 \\
\cline { 2 - 5 } & Average person GDP(RMB) & 54952 & 28411 & 16263 \\
\hline \multirow{2}{*}{2008} & The GDP share of total province (\%) & 61.9 & 18.3 & 19.8 \\
\cline { 2 - 5 } & Average person GDP(RMB) & 61823 & 33735 & 19555 \\
\hline
\end{tabular}

Table 2. Jiangsu three region's rate of urbanization from 2000 to 2008

\begin{tabular}{|c|c|c|c|c|}
\hline year & Province & Sunan region & Middle region & Subei region \\
\hline 2000 & $41.5 \%$ & $45.6 \%$ & $28.5 \%$ & $24.9 \%$ \\
\hline 2008 & $54.3 \%$ & $67.7 \%$ & $50.2 \%$ & $43.1 \%$ \\
\hline
\end{tabular}

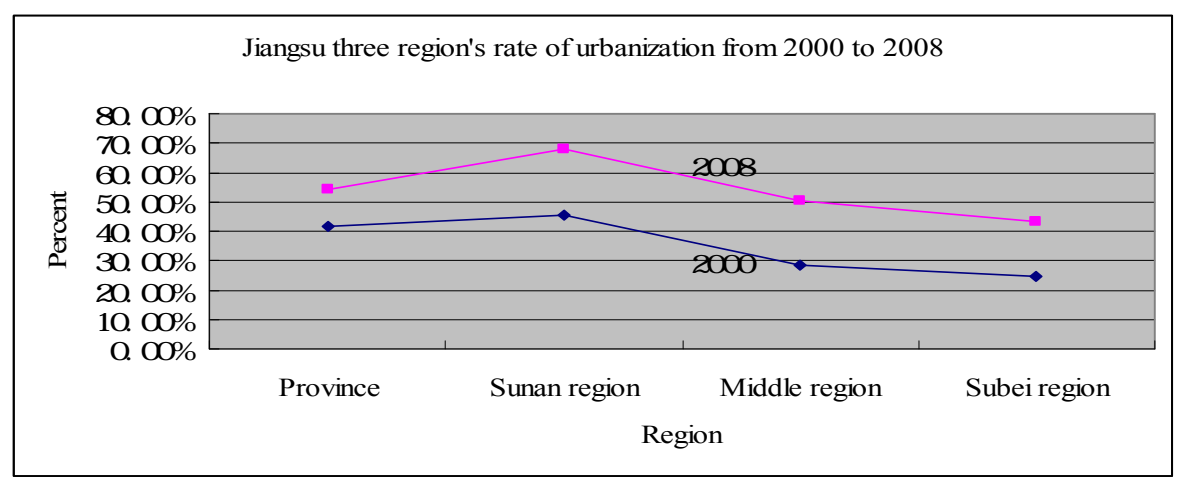

Figure 1. Jiangsu three region's rate of urbanization from 2000 to 2008 